\title{
Sistem Informasi Absensi berbasis WEB di Politeknik Negeri Padang
}

\author{
Alif Gilang Mulia ${ }^{1}$ \\ ${ }^{1}$ e-mail: alifgilang888@gmail.com, \\ ${ }^{1}$ Mahasiswa, D4 TRPL Politeknik Negeri Padang,
}

\begin{abstract}
Absensi adalah suatu kegiatan atau rutinitas yang dilakukan seseorang dosen untuk membuktikan bahwa mahasiswa hadir atau tidak dalam suatu kelas atau suatu pertemuan. Kehadiran mahasiswa menjadi salah satu penentu jika seorang mahasiswa ingin mendapatkan nilai atau hasil yang maksimal. Kendala-kendala yang terjadi pada pencatatan dan pelaporan absensi secara manual, diantaranya adalah kesalahan penulisan nama, ada kolom yang terlewatkan atau tidak diisi, lupa mencatat tanggal dan nama subject dan juga di kantor Registrasi harus menyediakan formulir absen kelas dalam bentuk kertas dengan jumlah quantity yang lebih banyak. Sistem informasi absensi berbasis web di Politeknik Negeri Padadng dibuat dengan harapan dapat membantu proses pelaporan absen setiap mahasiswa ke kantor registrar yang ada di Politeknik Negeri Padang. Adapun metode yang digunakan dalam penelitian ini yaitu mengguankan metode Prototype yang merupakan salah satu teknik pendekatan dalam pembuatan perangkat lunak. Analisis sistem menggunakan beberapa diagram Unified Modeling Language (UML) yaitu Use Case Diagram, Sequence Diagram, dan Activity diagram. Bahasa pemograman yang digunakan yaitu PHP dengan framework CodeIgniter dan database MySQL. Penelitian ini mengahasilkan suatu sistem informasi yang bisa digunakan dalam pelaporan absen mahasiswa di Politeknik Negeri Padang.
\end{abstract}

Kata Kunci- absen, web, mahasiswa, sistem informasi.

\section{PENDAHULUAN}

Politeknik Negeri Padang adalah politeknik negeri yang memiliki 7 Jurusan yaitu Teknik Sipil, Teknik Elektro, Teknik Mesin, Teknologi Informasi, Administrasi Niaga, Akuntansi, dan Bahasa Inggris.Untuk menunjang proses perkuliahan Politeknik Negeri Padang menggunakan Sistem Informasi Akademik (SIAK) digunakan untuk keperluan proses pendaftaran, mengatur dan mengecek absen, pengecekan jadwal matakuliah, nilai matakuliah yang sudah dikontrak dan informasi yang berhubungan dengan akademis.

Agar aktivitas perkuliahan dapat berlangsung dengan baik diperlukan pencatatan dan pelaporan absen dari dosen maupun mahasiswa. Sebagai dokumentasi kehadiran, pencatatan dan pelaporan absen mahasiswa digunakan sebagai bukti bahwa mahasiswa tersebut hadir di kelas atau tidak. Pencatatan dan pelaporan yang ada di Unklab masih dilakukan dengan cara manual sehingga memungkinkan terjadinya beberapa kendala, diantaranya adalah:

1. Kendala dalam mencatat nama mahasiswa dalam hal ini kesalahan penulisa nama, ada kolom yang terlewatkan atau tidak diisi.

2. Kendala dalam mencatat tanggal dan nama subject dalam hal ini lupa untuk menuliskan tanggal dan nama subject.

3. Kendala di Kantor Registrasi harus menyediakan formulir absen kelas dalam bentuk kertas dengan jumlah quantity yang lebih banyak.

Berawal dari uraian permasalahan di atas maka perlu untuk dibuatnya suatu sistem informasi pengambilan absen mahasiswa di Universitas Klabat yang diimplementasikan dalam bentuk perangkat lunak yang sudah menggunakan Komputer, maka pada penelitian ini, peneliti membuat "Sistem Informasi Absensi Berbasis Web di Politeknik Negeri Padang”. 


\section{LANDASAN TEORI}

\subsection{Absensi}

Absensi adalah suatu kegiatan atau rutinitas yang dilakukan oleh seseorang untuk membuktikan dirinya hadir atau tidak dalam suatu instansi. Absensi ini berkaitan dengan penerapan disiplin yang ditentukan oleh masing-masing perusahaan atau institusi.

Absensi sering menjadi permasalahan yang membosankan bagi para pencatat absensi dan merupakan salah satu kegiatan rutin yang harus dikerjakan dalam dunia akademis, Mengapa membosankan? Karena tiap hari para operator menghitung absensi masingmasing mahasiswa dalam kegiatan belajar-mengajar. Ketika ada mahasiswa yang mendapat Surat Peringatan $3 \mathrm{t}$ maka akan dikenakan sangsi berupa pemanggilan orang tua. Artinya para staff setiap hari akan melakukan rekap dari masingmasing kehadiran .

Karena absensi ini merupakan hal panting yang bisa dijadikan standar untuk menilai kerajinan seorang pelajar, maka peneliti harus teliti dalam membuat aplikasinya. Perancangan yang dibuat harus bisa memenuhi kebutuhan pengguna absensi.

\subsection{Pengertian Sistem}

Sistem adalah entitas atau satuan yang terdiri dari dua atau lebih komponen atau subsistem (sistem yang kecil) yang saling terhubung dan terkait untuk mencapai suatu tujuan.

\subsubsection{Pengertian Informasi}

Informasi adalah data yang telah diproses menjadi bentuk yang memiliki arti bagi penerima dan dapat berupa fakta, suatu nilai yang bermanfaat. Sumber informasi adalah data. Data adalah fakta kasar atau gambaran yang dikumpulkan dari keadaan tertentu.

\subsubsection{Pengertian Sistem Informasi}

Sistem informasi merupakan komponen yang saling terkait yang mengumpulkan, memanipulasi, menyimpan dan menyebarkan informasi serta memberikan feedbackuntuk memenuhi tujuan

\subsection{Framework Codelgniter}

Codeigniter adalah framework pengembangan web yang berbasis PHP, framework CodeIgniter memungkinkan penggunaa memakai PHP versi 4 atau 5 dalam pengembangan aplikasi menggunakan framework ini. Keunggulan utama yang dimiliki oleh CodeIgniter adalah

1. Sebuah framework applikasi.

2. Berjalan di PHP versi 4 dan 5 .

3. Ringan dijalankan karena kode program sederhana

4. Cepat untuk dijalankan

5. Menggunakan Konsep M-V-C (Model, View, Controller).

6. Menggunakan clean URLs.

7. Terdokumentasi dengan baik

8. Banyak pengguna yang menggunakan framework ini. 


\section{METODE PENELITIAN}

\subsection{Kerangka Teori}

Pada penelitian yang dilakukan, peneliti menggunakan proses model Prototyping.Alasan menggunakan proses model Prototyping, karena metode ini cocok dengan penelitian ini, dimana peneliti hanya memiliki waktu yang singkat (1 tahun) untuk melakukan penelitian sehingga membutuhkan pengembangan aplikasi yang cepat dan fleksibel dalam melakukan perubahan sewaktu-waktu ada error atau adanya penambah fitur

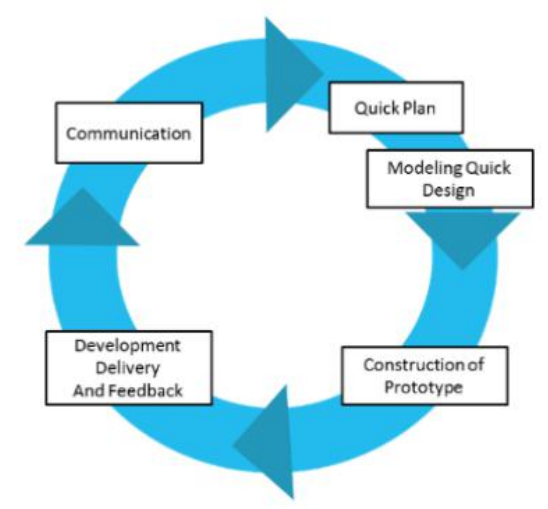

Gambar 1 Proses Model Prototyping

Pada gambar 1 merupakan tahapan dalam model prototyping. Model prototyping dimulai dari Communication, Quick Plan, Modelling Design, Construction of Prototype, Development Delivery and Feedback.

\subsection{Kerangka Konseptual Penelitian}

Berikut merupakan gambaran umum dari proses penelitian ini yang dapat dilihat pada gambar 2 .

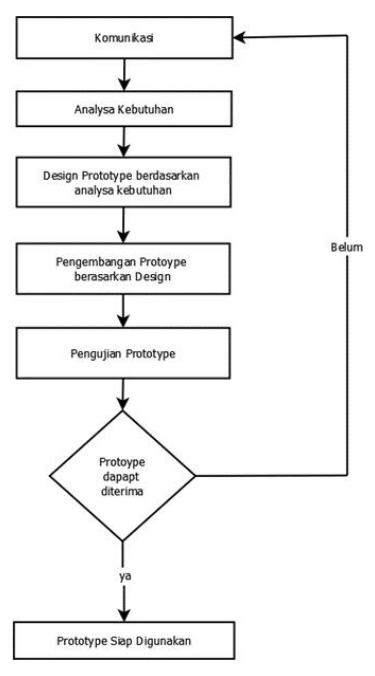

Berikut penjelasan tentang apa yang dilakukan pada setiap tahap:

1.Komunikasi

Pada tahap ini dilakukan komunikasi dengan stakeholder. Stakeholder adalah pihak yang terkait dalam pengembangan perangkat lunak ini yaitu dosen dan registrar. Komunikasi bertujuan untuk memperoleh informasi kebutuhan stakeholder atau dosen dan registrar.

2.Analisa kebutuhan 
Setelah proses komunikasi telah selesai dan telah diperoleh informasi kebutuhan dari para stakeholder, berikutnya dilakukan analisa dari informasi yang berhasil dikumpulkan.

3.Desain prototype berdasarkan analisa kebutuhan

Setelah dilakukan analisa, berikutnya adalah membangun perancangan atau desain dari perangkat lunak yang dikembangkan. Design ini berupa algoritma, arsitektur sistem, tampilan antar-muka, database (Struktur Data) dari perangkat lunak yang dikembangkan beserta fitur-fitur sementara yang tersedia dari perangkat lunak yang dibangun.

4.Pengembangan prototype berdasarkan desain

Desain atau perancangan prototype sudah dilakukan berikutnya adalah proses pengembangna prototype sesuai desain yang telah di buat. Desain yang ada di terjemahkan ke dalam bahasa pemograman yang sesuai.

5.Pengujian prototype

Tahap pengujian prototype dilakukan oleh pihak yang terkait atau stakeholder apabila proototype belum memenuhi kebutuhan yang diharapkan maka proses diulangi dari tahap komunikasi hingga prototype memenuhi kebutuhan yang diharapkan oleh stakeholder.

6.Prototype siap digunakan

prototype yang sudah memenuhi kebutuhan yang diharapkan siap digunakan.

\subsection{Deskripsi Sistem}

Sistem ini secara garis besar dapat memberikan informasi untuk Admin,Dosen User maupun secara umum. Dimana dapat diakses oleh 3 pengguna yaitu Admin(Registrar), Dosen User(Rektor, Warek I, II,III, Dekan, Kajur). Kerangka sistem dapat kita lihat pada Gambar 2.

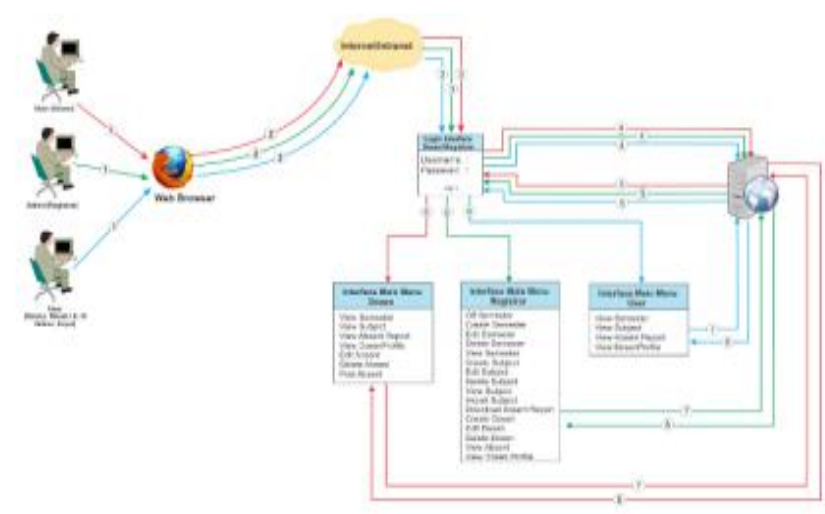

\section{Gambar 3 Kerangka Aplikasi}

Berikut merupakan penjelasan dari gambar 3 di atas: Berdasarkan gambar 3 cara kerja Sistem informasi absensi real-time berbasis web dibuat untuk dosen (panah merah), registrar (panah hijau), user (panah biru) dalam hal ini agar mudah dalam mengakses dan melakukan operasi CRUD pada sistem informasi SIAK PNP.

a. Halaman Web (tanda panah hijau)

1. Registrar mengakses halaman web lewat web browser pilihan mereka.

2. Dibutuhkan akses internet untuk dapat membuka halaman web SIAK PNP

3. Setelah terkoneksi internet, halaman web dapat diakses, dan akan ditampilkan menu login untuk dapat masuk menggunakan layanan di web.

4. Registrar memasukan username dan password lalu halaman web akan mengautentikasi data yang dimasukan dengan mencocokkannya pada database absensi.

5. Hasil yang didapat dikembalikan ke halaman web.

6. Apabila hasil yang didapat berhasil, maka dosen dapat masuk ke halaman web 
absensi real-time Unklab.

7. Aplikasi lalu mengambil data dari database absensi.

8. Data yang didapat ditampilkan pada halaman web absensi real-time unklab.

b. Halaman Web (tanda panah merah)

1. Dosen mengakses halaman web lewat web browser pilihan mereka

2. Dibutuhkan akses internet untuk dapat membuka halaman web ART UNKLAB

3. Setelah terkoneksi internet, halaman web dapat diakses, dan akan ditampilkan menu login untuk dapat masuk menggunakan layanan di web.

4. Dosen memasukan username dan password lalu halaman web akanmengautentikasi data yang dimasukan dengan mencocokkannya pada database absensi .

5. Hasil yang didapat dikembalikan ke halaman web.

6. Apabila hasil yang didapat berhasil, maka dosen dapat masuk ke halaman web absensi Web PNP.

7. Aplikasi lalu mengambil data dari database absensi.

8. Data yang didapat ditampilkan pada halaman web absensi WEB PNP.

c. Halaman Web(tanda panah biru)

1. User (Direktur,Wadir I,II,III,Kajur,Dosen) mengakses halaman web lewat web browser pilihan mereka

2. Dibutuhkan akses internet untuk dapat membuka halaman web AWEB PNP

3. Setelah terkoneksi internet, halaman web dapat diakses, dan akan ditampilkan menu login untuk dapat masuk menggunakan layanan di web.

4. User memasukan username dan password lalu halaman web akan mengautentikasi data yang dimasukan dengan mencocokkannya pada database absensi.

5. Hasil yang didapat dikembalikan ke halaman web.

6. Apabila hasil yang didapat berhasil, maka user dapat masuk ke halaman web absensi WEB PNP.

7. Aplikasi lalu mengambil data dari database absensi.

8. Data yang didapat ditampilkan pada halaman web absensi WEB PNP.

\section{IV.PEMBAHASAN}

Bagian ini akan menjelaskan tentang implementasi dari sistem informasi absensi real-time di Universitas Klabat. Peneliti menggunakan Unified Modelling Language (UML) yang terdiri dari class diagram, use case diagram, activity diagram, dan sequence diagram. Peneliti menggunakan UML karena dengan UML dapat dengan mudah untuk menggambarkan dan mendeskripsikan interaksi yang terjadi antar pengguna dan sistem.

\subsection{Use Case}

Use case diagram ini menjelaskan interaksi antara admin dosen dan user dengan sistem. Pada gambar 4 merupakan Use Case

Diagram dari sistem yang akan dibuat. Use Case Diagram terdiri dari 3 aktor dan 26 use case.

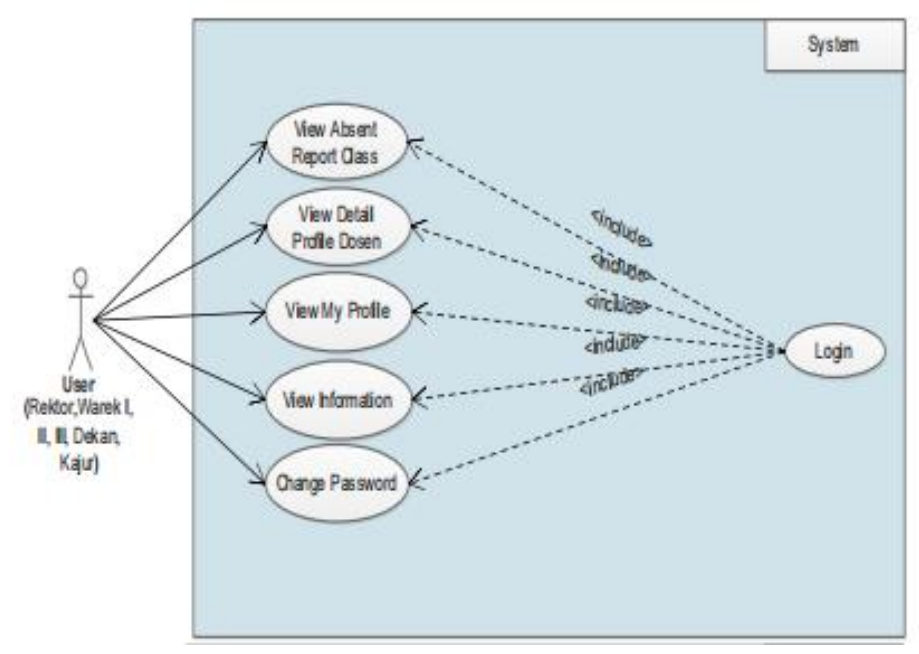



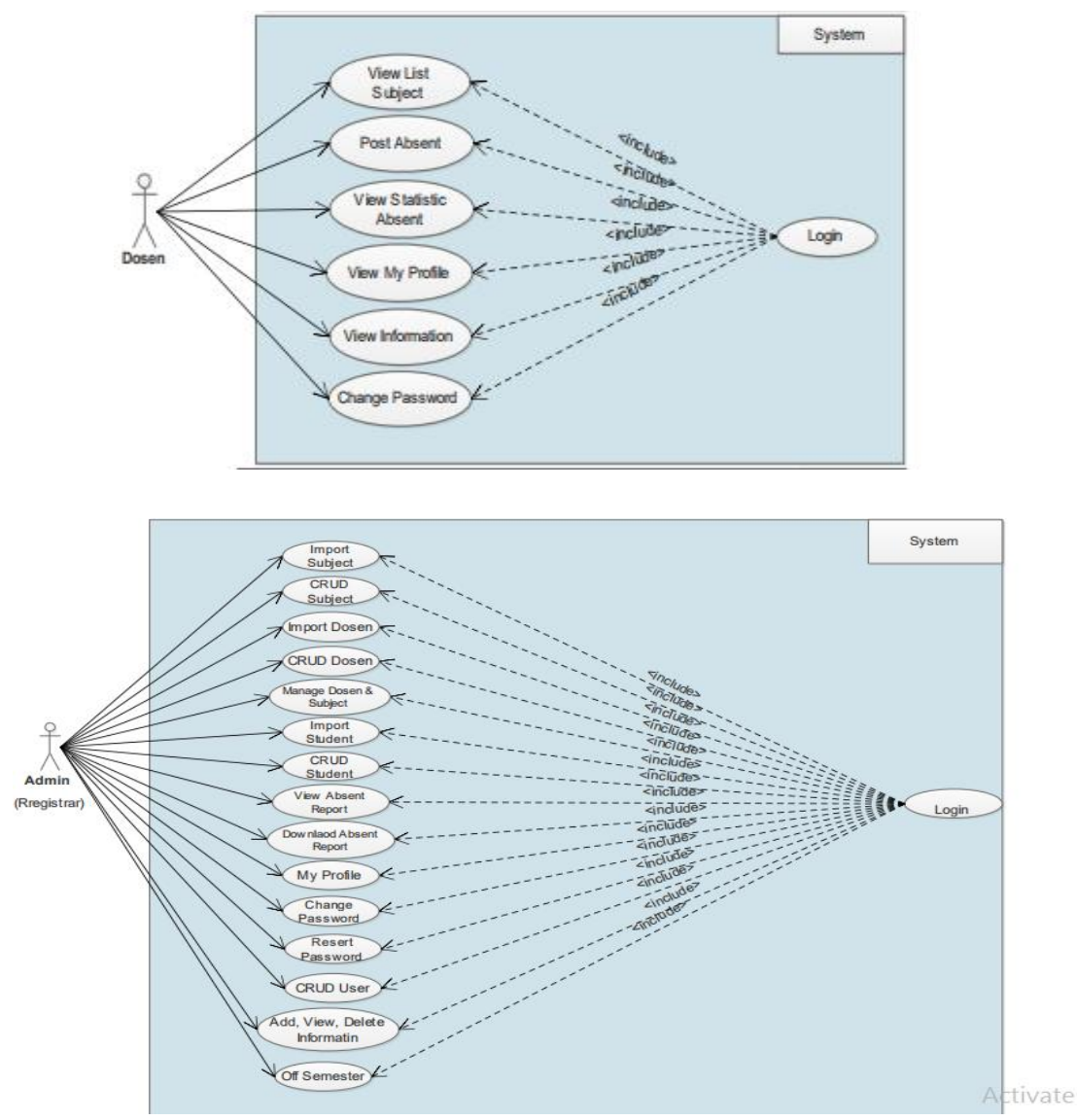

Gambar 4 Use Case Diagram Admin, Dosen User

\subsection{Class Diagram}

Class Diagram adalah spesifikasi yang menggambarkan struktur dari sebuah sistem untuk menunjukan kelas-kelas sistem, atribut dan hubungan diantara kelas tersebut.

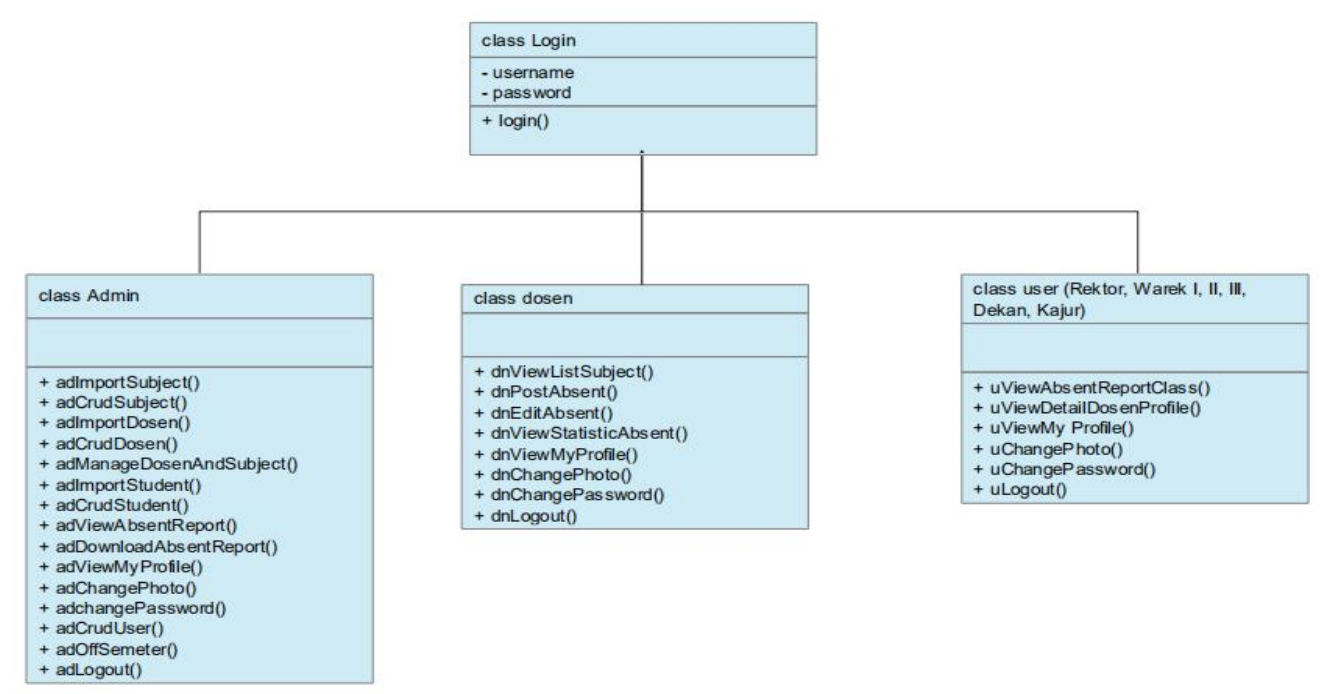

Gambar 5 Class Diagram Sistem Informasi Absensi WEB di Politeknik Negeri Padang. 


\section{KESIMPULAN}

1. Absensi Berbasis Web dapat mengurangi masalah, dimana sering terjadinya mahasiswa "Gaib".

2. Mengurangi penggunakan kertas untuk pengambilan absen manual.

3. Mencegah adanya tindakan curang TA(Titip Absen).

4. Memudahkan Dosen ataupun pegawai akademik dalam merekap absen.

5. Memiliki kekurangan yaitu harus memiliki jaringan internet serta memiliki device yg compatiteble dengan browser yang digunakan.

6. Hasil absen dapat di download dan dicetak dalam bentuk PDF.

\section{REFERENSI}

[1] R. S. Roger, Rekayasa Perangkat Lunak, 7th ed, Yogyakarta: Andy, 2012.

[2] R. S. Pressman, Software Engineering A Practitioner's Approach, vol. 7th, New York: McGraw-Hill, 2010.

[3] A. Saputra, Pengenalan Sistem Aplikasi Absensi, Jakarta, Indonesia: PT. Elex Media Komputindo, 2012.

[4] D. Anwar, Kamus Lengkap Bahasa Indonesia Terbaru, Surabaya: Amelia, 2003.

[5] K. Herlinda, "Sistem Informasi Akademik Terpadu Sekolah Tarbiyah Muara Enim Mengunakan PHP\&MYSQL",2011.s

[6] J. Laudan and K. Laudon, Management Information System Managing Digital Firm, vol 12th, New Jersey: Pearson Education,Inc,2012.

[7] R. Stair and G. Reynolds, Fundamentals of Information Systems 7th Edition, USA: Cencage Learning, 2014. 